\title{
PLANNING COST PRODUCTION PATROL BOAT TYPE V21 FIBER GLASS
}

\author{
M. Rusdy Hatuwe ${ }^{1}$, Amir Marasabessy ${ }^{2}$, Sugeng Prayitno ${ }^{3}$ \\ Program Studi Teknik Perkapalan, Universitas Pembangunan Nasional “Veteran” Jakarta, Jakarta Selatan 123 \\ email ${ }^{1}$ : mohrushhat@rocketmail.com
}

\begin{abstract}
Development of fleet of patrol boats by the Ministry of Sea Transportation as an effort to supervise Indonesian territorial waters, especially in remote areas to prevent illegal fishing by neighboring fishing vessels where from October 2014 to 1 April 2017 there are 317 fishing vessels of neighboring countries that have been drowned, with details of Vietnam 142 vessels, Philippines 76 ships, Thailand 21 ships, Malaysia 49 ships, Indonesia 21 ships, Papua New Guinea 2 ships, China 1 ship, Belize 1 vessel and no country 4 ships Production cost planning needs to be carefully scrutinized, if the production cost budget is too big ship production Not economical otherwise if too small can affect the quality of ship production. The objective of the research is to make a budget production plan of V21 patrol boat type of fiber glass material, where the material and equipment of ship component is marine use with the price referring to current rupiah exchange rate, so it is expected to be guaranteed economic value and ship production quality. The method used in production cost planning is the unit price survey of materials and equipment / equipment of ship components with reference to general arrangement design drawings, mindset section and technical specifications. Based on the result of research, production cost of ship patrol vessel type V21 fiber glass Rp.554.720.000, - while the cost of making molded and hull and deck unit Rp.174.220.000, -
\end{abstract}

Keywords: patrol boat, fiber glass, production cost, production quality

\section{PENDAHULUAN}

Kebijakan pemerintah untuk menjadikan negara Republik Indonesia sebagai poros maritim dunia merupakan suatu kebijakan positif yang perlu didukung oleh masyarakat Indonesia termasuk dari kalangan akademisi terutama dibidang kemaritiman dan bahari. Sebagai langkah konkrit pemerintah yang berkaitan dengan hal tersebut adalah pencegahan ilegal fishing dengan melakukan penangkapan dan peneggelaman kapal ikan negara tetangga yang mengambil ikan secara ilegal di perairan wilayah Indonesia dan hingga Oktober 2014 sampai dengan 1 April 2017 ada 317 kapal ikan negara tetangga yang telah ditenggelamkan, dengan rincian Vietnam 142 kapal, Filipina 76 kapal, Thailand 21 kapal, Malaysia 49 kapal, Indonesia 21 kapal, Papua Nugini 2 kapal, China 1 kapal, Belize 1 kapal dan tanpa negara 4 kapal, akan tetapi dengan perairan wilayah Indonesia yang begitu luas maka sangat dimungkinkan adanya ilegal fishing yang tidak diketahui. Sehubungan dengan hal ini maka perlu dilakukan pengawasan perairan wilayah Indonesia secara terintegrasi dan terpadu dengan melibatkan pihak-pihak yang terkait, diantaranya pengembangan dan pengadaan berbagai jenis kapal patroli yang sangat dibutuhkan dalam melakukan pengawasan perairan di berbagai wilayah di Indonesia terutama didaerah terpencil.

Kementrian Perhubungan dan Kelautan dan Perikanan (KKP) Republik Indonesia dalam pengembangan armada kapal patroli perairan diwilayah Indonesian hingga saat ini dirasakan masih kurang, hal ini ditunjukan dengan semakin meningkatnya jumlah kapal-kapal ikan negara tetangga yang leluasa bisa masuk ke perairan Indonesia untuk melakukan pencurian ikan secara ilegal.

Sehubungan dengan hal tersebut perlu dilakukan penambahan armada kapal patroli kecil dan sedang terutama yang dapat dioperasikan di daerahdaerah terpencil, dan hal ini tentunya berkaitan dengan perencanaan anggaran biaya produksi yang perlu dicermati secara seksama karena selama ini anggaran biaya produksi kapal patroli fiber glass dibuat dengan memperkirakan harga dengan mengacu pada rencana anggaran biaya yang sudah ada, baik untuk bahan fiber glass maupun peralatan/perlengkapan komponen kapal sehingga dapat mengakibatkan biaya produksi kapal menjadi tidak ekonomis dan hal ini berpeluang akan terjadi penyalahgunaan anggaran biaya produksi oleh pihakpihak yang berkepentingan atau dapat mempengaruhi 
kualitas produksi kapal. Hal ini mengakibatkan ada beberapa galangan kapal fiber glass yang tidak mau menerima order produksi kapal patroli fiber glass karena mengalami kerugian \pm antara (10 s/d 20) \% dari nilai kontrak, disatu sisi galangan kapal dalam mempertahankan kualitas produksi kapal dengan pembelian bahan dan peralatan/perlengkapan komponen kapal yang marine use tapi disisi lain harga satuan yang tercantum dalam rencana anggaran biaya produksi bukan yang marine use sehingga dalam penelitian ini akan dilakukan pendekatan dengan melakukan survei harga satuan bahan/material dan dan peralatan/perlengkapan komponen kapal yang marine use agar dapat merencanakan biaya produksi kapal yang tepat dan akurasi. Tujuan dari penelitian ini adalah membuat rencana anggaran biaya produksi kapal patroli fiber glass tipe $V_{21}$ dimana bahan dan peralatan/perlengkapan komponen kapal adalah marine use dengan harga yang mengacu pada nilai kurs rupiah saat ini, sehingga dapat bermanfaat bagi pihak yang terkait dalam penyusunan anggaran biaya produksi kapal patroli fiber glass agar dapat terjamin baik kuantitas maupun kualitas produksi kapal. Saat ini biaya produksi kapal patroli tipe $V_{21}$ berbahan fiber glass dengan kapasitas penumpang 8 orang dengan mesin 2 x 85 Hp tipe IBM berkisar antara 700 juta s/d 750 juta.

Penelitian yang telah dilakukan sebelumnya adalah membuat proyek inovasi perencanaan kapal motor pesiar berbahan fiber glass OBM 2 x 85 HP kapasitas angkut 8 orang (Amir Marasabessy, 2014), Desain kapal ikan sederhana berbahan fiber glass (Amir Marasabessy, 2010) dan Perencanaan biaya produksi kapal ikan 30 GT tipe purse seine berbahan fiber glass dengan sistem pendingin fish hold (Rusdy hatuwe, 2016). Metode yang digunakan dalam penelitian ini adalah survei harga satuan bahan/material dan peralatan/perlengkapan kapal yang marine use, yang diawali dengan perencanaan kebutuhan bahan fiber glass menggunakan program software berdasarkan desain gambar midhip section dan lines plan, sedangkan untuk kebutuhan peralatan/perlengkapan komponen kapal akan mengacu pada gambar general arrangement dan spesifikasi teknis dengan memperhitungkan biaya margin.

\section{TINJAUAN PUSTAKA \\ Roadmap Penelitian}

Penelitian tentang Rencana Anggaran Biaya Produksi kapal merupakan bagian dari perencanaan kapal. Berkaitan dengan perencanaan biaya produksi kapal patroli tipe $\mathrm{V}_{21}$ berbahan fiber glass memiliki Roadmap penelitian sebagaimana yang diperlihatkan pada gambar 1. Penelitian tentang perencanaan kapal yang telah dilakukan sebelumnya berupa perencanaan kapal ikan sederhana berbahan fiber glass yang telah dituangkan dalam jurnal Bina Widya UPN "Veteran" Jakarta Volume 20, Nomor 3, Nopember 2010. ISSN :0853-2621 dan perencanaan dan produksi proyek inovasi kapal motor pesiar berbahan fiber glass OBM 2 x85 HP yang telah didaftarkan pada Kementrian Hukum dan HAM Republik Indonesia sebagai HKI Desain Industri dengan No.pendaftaran: IDD0000042727 yang berlaku selama 10 tahun terhitung sejak tanggal 29 Oktober 2014 serta Perencanaan biaya produksi kapal ikan 30 GT tipe purse seine berbahan fiber glass dengan sistem pendingin fish hold yang juga telah dituangkan dalam e-jurnal Bina Teknika Fakultas Teknik UPNVJ, Volume 13, No.1 edisi Juni 2017.

\section{General Arrangement}

Gambar general arrangement adalah gambar yang didesain untuk memperlihatkan Peralatan/perlengkapan kapal, perlengkapan keselamatan, perlengkapan tambat, perlengkapan navigasi/komunikasi, deck machinery, pembagian ruangan/akomodasi sebagainya.

\section{Midship Section dan Lines Plan}

Gambar midship section adalah gambar yang didesain untuk memperlihatkan ukuran profil dan ketebalan pelat dari pelat keel sampai dengan pelat sisi, pelat deck dan dinding bangunan atas disamping memperlihatkan metode penyambungan konstruksi, sedangkan lines plan adalah gambar proyeksi tiga dimensi yakni proyeksi gading, proyeksi water line dan proyeksi butock line.

\section{Spesifikasi Teknis dan Rencana Anggaran Biaya}

Spesifikasi Teknis adalah petunjuk teknis untuk pelaksanaan pekerjaan produksi yang memuat antara lain jumlah layer dari bahan fiber glass untuk bagianbagian konstruksi. Menjelaskan merek/jenis/kapasitas/jumlah dari bahan/material dan peralatan/perlengkapan bagian komponen kapal secara menyeluruh yang akan digunakan dengan standard marine use.

Rencana Anggaran Biaya (RAB) adalah untuk memperlihatkan harga satuan dan kuantitas dari bahan/material produksi dan peralatan/perlengkapan komponen kapal dan sebagai petunjuk untuk pembelian bahan/material dan peralatan/perlengkapan bagian komponen kapal.

\subsection{Bahan Utama Fiber glass}

Bahan utama fiberglass yang digunakan untuk rencana anggaran biaya produksi kapal sebagaimana yang diperlihatkan pada gambar 2. dimana jumlah kebutuhan untuk produksi ditentukan dengan menggunakan maxsurf programe. 

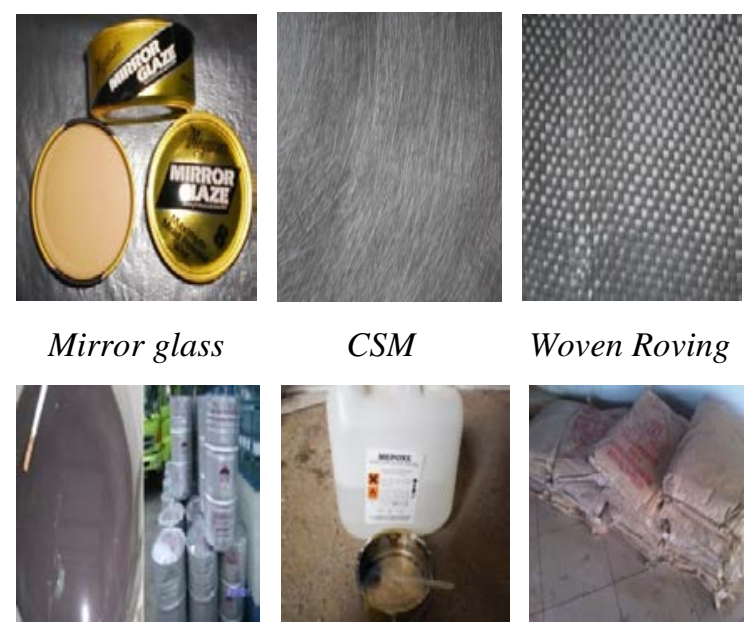

CSM

Woven Roving
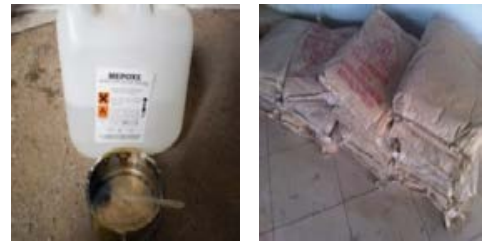

Resin BQTN 157

Katalis
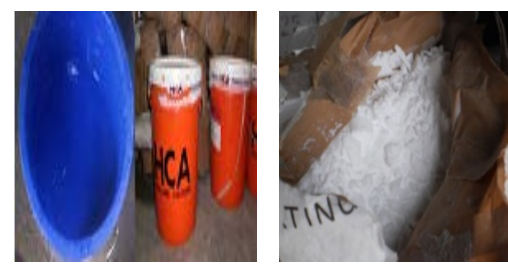

Talk

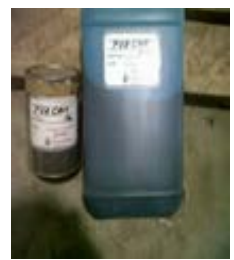

Gelcoat-pigment

Herosil

Cobalt

Gambar 1. Bahan utama fiber glass untuk produksi kapal

\section{METODOLOGI PENELITIAN \\ Lokasi Penelitian}

Penelitian dilakukan di galangan kapal fiber glass CV.Cisanggarung Putra Mandiri di Marunda Jakarta Utara sesuai gambar 2. dengan kegiatan usaha pelayanan jasa produksi bangunan baru dan reparasi kapal berbahan fiber glass.

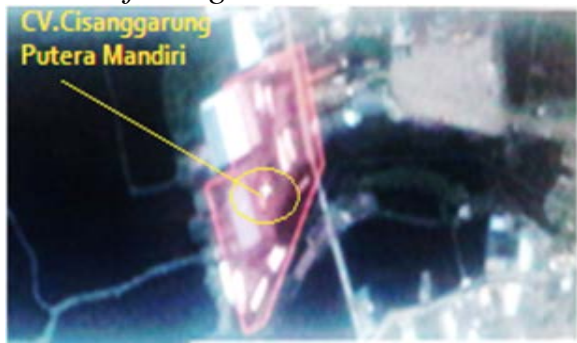

Gambar 2. Lokasi penelitian

\section{Alat dan Bahan}

Peralatan yang digunakan berupa laptop, printer berikut catrid black/color, software maxsurf, programming Excel, kertas HVS 70 gram 2 rim

\section{Tahapan Penelitian}

Adapun tahapan penelitian secara keseluruhan dalam waktu 8 bulan sebagaimana yang diperlihatkan pada gambar 3 .

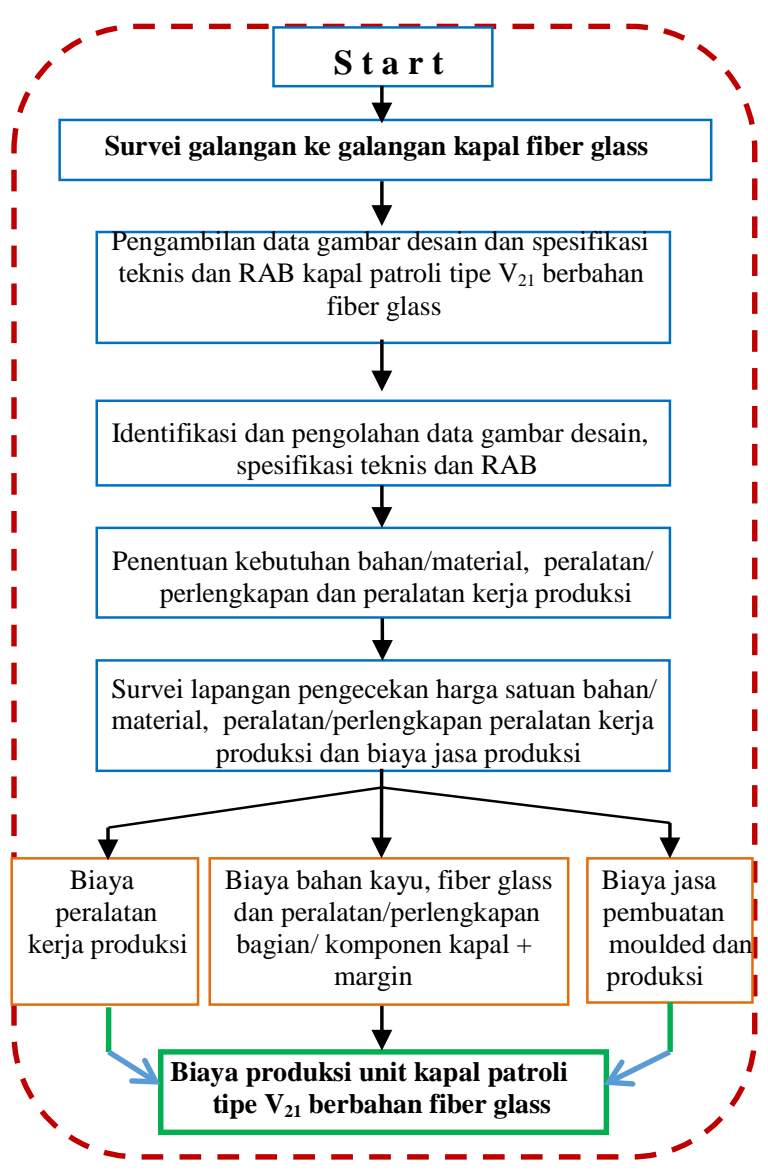

Gambar 3. Diagram tahapan penelitian

\section{HASIL DAN PEMBAHASAN}

\section{Hasil Survei Lapangan}

a. Data kapal

1). Ukuran pokok kapal

Panjang Sekluruh (Loa) : 7,00 [m]

Panjang garis Air (Lwl) : 6,73 [m]

Lebar Kapal (B) : $1,90[\mathrm{~m}]$

Tinggi Geladak (D) $\quad: 0,80[\mathrm{~m}]$

Tinggi Sarat $(\mathrm{d}) \quad: 0,30[\mathrm{~m}]$

Coefficient block $(\mathrm{Cb}) \quad$ : 0,38

Displacement $(\underline{\Lambda}) \quad: 1,37$ [ton]

Kapasitas angkut $\quad: 8$ orang

Mesin penggerak (OBM) : 2 x $85 \mathrm{HP}$

2). Gambar lines plan, midship section dan general arrangement

Gambar rencana garis (lines plan) berikut dengan pemodelan dan rencana umum (general arrangement) dan construction kapal patroli tipe $\mathrm{V}_{21}$, diperoleh di galangan kapal fiber glass sebagaimana yang diperlihatkan pada gambar 5, gambar 6 dan gambar 7.

b. Kebutuhan bahan untuk pembuatan moulded parmanen dan produksi hull dan deck

Kebutuhan bahan kayu dan fiber glass untuk pembuatan cetakan (moulded) parmanen serta produksi hull dan deck, ditentukan berdasarkan gambar lines plan, midship section dan general 
arrangement sebagaima yang diperlihatkan pada tabel.1

Tabel.1 Kebutuhan bahan kayu dan fiber glass untuk moulded parmanen serta unit produksi hull dan deck

\begin{tabular}{|c|c|c|}
\hline No & Material kayu dan fiber glass & Jumlah \\
\hline A. & \multicolumn{2}{|l|}{ Material kayu } \\
\hline 1 & Balok kayu 5 × 7 × $400 \mathrm{~cm}$ & $12 \mathrm{btg}$ \\
\hline 2 & Reng 3 × 4 × $400 \mathrm{~cm}$ & $45 \mathrm{btg}$ \\
\hline 3 & Kaso 6 × 4 × $400 \mathrm{~cm}$ & $20 \mathrm{btg}$ \\
\hline 4 & Papan 2 x 20 x 400 cm & $20 \mathrm{lbr}$ \\
\hline 5 & Melamin warna putih $3 \mathrm{~mm}$ & $14 \mathrm{lbr}$ \\
\hline 6 & Triplek 3 mm & $14 \mathrm{lbr}$ \\
\hline 7 & Lem I bond & $20 \mathrm{klg}$ \\
\hline 8 & Dempul @5kg, per 4 kaleng/dus & 4 dus \\
\hline 9 & Paku 1 inch & $5 \mathrm{~kg}$ \\
\hline 10 & Paku 11/2 inch & $5 \mathrm{~kg}$ \\
\hline 11 & Paku 2 inch & $5 \mathrm{~kg}$ \\
\hline 12 & Paku 3 inch & $5 \mathrm{~kg}$ \\
\hline 13 & Amplas uk.220,400 dan $800 @ 50$ lbr & $50 \mathrm{lbr}$ \\
\hline B. & \multicolumn{2}{|l|}{ Material fiber glass } \\
\hline 1 & Mirror wax & $11 \mathrm{~kg}$ \\
\hline 2 & Gelcoat & $45 \mathrm{~kg}$ \\
\hline 3 & Pigment LR sesuai warna kapal & $6 \mathrm{~kg}$ \\
\hline 4 & Pigment LR warna hitam (moulded) & $2 \mathrm{~kg}$ \\
\hline 5 & Chopped Strand Mat300 & $100 \mathrm{~kg}$ \\
\hline 5 & Chopped Strand Mat450 & $220 \mathrm{~kg}$ \\
\hline 6 & Woven Roving 600 & $255 \mathrm{~kg}$ \\
\hline 7 & Polyester Resin BQTN 157 & $1300 \mathrm{~kg}$ \\
\hline 8 & Cobalt & $2 \mathrm{~kg}$ \\
\hline 9 & Catalyst & $23 \mathrm{~kg}$ \\
\hline 10 & Talk lioning & $70 \mathrm{~kg}$ \\
\hline 11 & PVA Liquid & $4 \mathrm{~kg}$ \\
\hline 12 & Dempul @5 kg, per 4 kaleng/dus & 2 dus \\
\hline 13 & Aceton & $10 \mathrm{~kg}$ \\
\hline 14 & Epoxy primer paint & $5 \mathrm{~kg}$ \\
\hline 15 & Cat anti fouling & $5 \mathrm{~kg}$ \\
\hline 16 & Cat finishing & $12 \mathrm{~kg}$ \\
\hline 17 & Thiner & 8 ltr \\
\hline 18 & Kain majun & $100 \mathrm{~kg}$ \\
\hline
\end{tabular}

Hal ini mengacu pada komposisi bahan fiber glass (tabel.2) sesuai standarisasi Badan Klasifikasi pada temteratur $28^{\circ} \mathrm{C}$ dan jumlah layer sesuai perencanaan (tabel.3) sebagai berikut:

Tabel 2. Komposisi laminasi fiber glass

\begin{tabular}{|c|l|l|}
\hline $\begin{array}{c}\text { Jenis } \\
\text { laminasi }\end{array}$ & $\begin{array}{c}\text { Bahan } \\
\text { fiber glass }\end{array}$ & \multicolumn{1}{c|}{$\begin{array}{c}\text { Perbandingan } \\
\text { terhadap resin }\end{array}$} \\
\hline \multirow{3}{*}{$\begin{array}{c}\text { Serat } \\
\text { fiber glass }\end{array}$} & Katalis & $(1-1,5) \%$, kondisi tertentu $~ 5 \%$ \\
\cline { 2 - 3 } & $\mathrm{CSM}_{300}$ & $(0,9-1,0) \mathrm{kg} / \mathrm{m}^{2}$ \\
\cline { 2 - 3 } & $\mathrm{CSM}_{450}$ & $(1,1-1,2) \mathrm{kg} / \mathrm{m}^{2}$ \\
\cline { 2 - 3 } & $\mathrm{WR}$ & $(1,5-1,6) \mathrm{kg} / \mathrm{m}^{2}$ \\
\hline \multirow{3}{*}{$\begin{array}{c}\text { Pembuatan } \\
\text { gelcoat }\end{array}$} & Pigment & $(8,0-10) \%$ \\
\cline { 2 - 3 } & Aerosil & $(0,6-1,0) \%$ \\
\cline { 2 - 3 } & Cobalt & $(1,0-1,5) \%$ \\
\hline
\end{tabular}

Tabel 3. Tebal laminasi sesuai standarisasi

\begin{tabular}{|c|c|c|c|}
\hline No & Item & Material & Layer \\
\hline \multicolumn{4}{|c|}{ Hull } \\
\hline 1 & Keel plate & $\mathrm{G}+\mathrm{M}_{300}+3 \mathrm{M}_{450}+3 \mathrm{WR}_{800}$ & 8 \\
\hline 2 & Bottom plate & $\mathrm{G}+\mathrm{M}_{300}+3 \mathrm{M}_{450}+2 \mathrm{WR}_{800}$ & 7 \\
\hline 3 & Shell plate & $\mathrm{G}+\mathrm{M}_{300}+2 \mathrm{M}_{450}+2 \mathrm{WR}_{800}$ & 6 \\
\hline 4 & Chine & $\mathrm{G}+\mathrm{M}_{300}+5 \mathrm{M}_{450}+4 \mathrm{WR} \mathrm{R}_{800}$ & 6 \\
\hline \multicolumn{4}{|c|}{ Deck } \\
\hline 1 & Sandwich Const. & $\begin{array}{l}\mathrm{G}^{+} \mathrm{M}_{300}+2 \mathrm{M}_{450}+1 \mathrm{WR}_{800^{+}} \\
\text {Plywood } 9 \mathrm{~mm}\end{array}$ & 5 \\
\hline \multicolumn{4}{|c|}{ Bulkhead } \\
\hline 1 & Single skin & $3 \mathrm{M}_{450}+2 \mathrm{WR}_{800}$ & 5 \\
\hline 2 & Bulkd.Stiffener & $3 \mathrm{M}_{450}+\mathrm{WR}_{800}$ & 4 \\
\hline \multicolumn{4}{|c|}{ Frames } \\
\hline 1 & Transv. Frame & $3 \mathrm{M}_{450}+2 \mathrm{WR}_{800}$ & 5 \\
\hline 2 & Side Longt. & $3 \mathrm{M}_{450}+2 \mathrm{WR}_{800}$ & 5 \\
\hline 3 & Girders & $3 \mathrm{M}_{450}+2 \mathrm{WR}_{800}$ & 5 \\
\hline 4 & Floors & $\mathrm{M}_{300}+2 \mathrm{M}_{450}+\mathrm{WR}_{800}$ & 4 \\
\hline \multicolumn{4}{|c|}{ Beams } \\
\hline 1 & Transv. Beam & $3 \mathrm{M}_{450}+2 \mathrm{WR}_{800}$ & 5 \\
\hline 2 & Longit. Beam & $3 \mathrm{M}_{450}+2 \mathrm{WR}_{800}$ & 5 \\
\hline & Tanks & $\mathrm{M}_{300}+3 \mathrm{M}_{450}+3 \mathrm{WR}_{800}$ & 7 \\
\hline \multicolumn{4}{|c|}{ Superstructure } \\
\hline 1 & Shell laminate & $\mathrm{M}_{300}+2 \mathrm{M}_{450}+\mathrm{WR}_{800}$ & 4 \\
\hline 2 & Front Wall & $\mathrm{M}_{300}+3 \mathrm{M}_{450}+2 \mathrm{WR}_{800}$ & 6 \\
\hline 3 & Stiffener & $\mathrm{M}_{300}+2 \mathrm{M}_{450}+\mathrm{WR}_{800}$ & 4 \\
\hline
\end{tabular}

\section{c. Kebutuhan peralatan kerja produksi}

Kebutuhan peralatan kerja produksi dengan jenis dan kuantitasnya ditentukan sesuai jumlah tenaga kerja dan waktu pelaksanaan produksi sebagaimana yang diperlihatkan pada tabel.4

Tabel.4 Kebutuhan peralatan kerja produksi

\begin{tabular}{|r|l|r|}
\hline No. & \multicolumn{1}{|c|}{ Peralatan kerja } & Jumlah \\
\hline 1. & Gayung 1 liter & $10 \mathrm{bh}$ \\
2. & Ember 5 ltr & $5 \mathrm{bh}$ \\
3. & Gagang roll bulu & $7 \mathrm{pcs}$ \\
4. & Isi kuas roll bulu & $4 \mathrm{lsn}$ \\
5. & Kuas cat ukuran . 2 inch dan 3 inch & $4 \mathrm{lsn}$ \\
6. & Sarung tangan & $3 \mathrm{lsn}$ \\
7. & Masker kain & $10 \mathrm{lsn}$ \\
8. & Sabun cream & $5 \mathrm{~kg}$ \\
9. & Benang putih & $2 \mathrm{roll}$ \\
10. & Spidol/pensil & $2 \mathrm{lsn}$ \\
11. & Mata gurinda potong 3 inch & $10 \mathrm{lsn}$ \\
12. & Mata gurinda ampals 3 inch & $10 \mathrm{lsn}$ \\
\hline
\end{tabular}

d. Kebutuhan peralatan/perlengkapan kapal

Kebutuhan peralatan/perlengkapan kapal, ditentukan berdasarkan gambar general arrangement dan spesifikasi teknis kapal pembanding sebagaimana yang diperlihatkan pada tabel.5 
Tabel.5 Kebutuhan peralatan/perlengkapan kapal

\begin{tabular}{|c|c|c|}
\hline No & Item peralatan/perlengkapan kapal & Jumlah \\
\hline A. & Perlengkapan Deck & \\
\hline 1 & Railing st.steel dia 1" & 1 Set \\
\hline 2 & Kawat las st. steel & $10 \mathrm{~kg}$ \\
\hline 3 & Plat st. steel $\mathrm{t}=4 \mathrm{~mm}$ & $1 / 2 \mathrm{~m} 2$ \\
\hline 4 & Baut stainless steel uk. 5-12 mm & 100 pcs \\
\hline 5 & Sekrup stainless steel uk.3-6 mm & 50Pcs \\
\hline 6 & Silikon SIKA & 5 btl \\
\hline 7 & Karpet bekleding dinding plafon & $10 \mathrm{~m} 2$ \\
\hline 8 & spoon bekled & $10 \mathrm{~m} 2$ \\
\hline 9 & Kursi pilot & 1 unit \\
\hline 10 & Kursi crew fiberglass & 6 org \\
\hline 11 & Pintu locker-locker kayu & 1 set \\
\hline 12 & Pintu utama & 1 set \\
\hline 13 & engsel2 st. steel & 4 set \\
\hline 14 & Kaca tempered sesuai GA & 1 paket \\
\hline 15 & Bolder st. steel 3 inch & 3 unit \\
\hline 16 & Lem I bond & $10 \mathrm{~kg}$ \\
\hline 17 & handel pintu & 1 set \\
\hline 18 & handel locker dan almari & 3 set \\
\hline 19 & Roller jangkar $10^{\prime \prime}$ & 1 Unit \\
\hline B. & Mesin Penggerak dan Perlengkapan & \\
\hline 1 & Mesin Outboard 85 PK, 2 Tak & 2 Unit \\
\hline 2 & $\begin{array}{l}\text { Kemudi system hydraulic \& controll } \\
\text { mesin }\end{array}$ & 1 Set \\
\hline 3 & Instalasi system pipa bahan bakar & 1 Set \\
\hline 4 & Instalasi Permesinan & 1 Set \\
\hline 5 & Filter bahan bakar + slang & 1 paket \\
\hline 6 & Pompa bilge & $1 \mathrm{pCS}$ \\
\hline C. & Perlengkapan Listrik & \\
\hline 1 & Kabel system DC, 1.5 x 2 & $200 \mathrm{mtr}$ \\
\hline 2 & Skun kabel & 50 pcs \\
\hline 3 & Saklar dan stop kontak & $1 \mathrm{set}$ \\
\hline 4 & Lampu penerangan & 4 set \\
\hline 5 & Panel listrik dan navigasi & 1 unit \\
\hline 6 & Batterey $150 \mathrm{AH}$ & 2 unit \\
\hline D. & Perlengkapan Navigasi/Komunikasi & \\
\hline 1 & Railing st.steel dia 1" & 1 Set \\
\hline 1 & Lampu Navigasi & 5 unit \\
\hline 2 & Klakson & 1 unit \\
\hline 3 & Lampu sorot DC $200 \mathrm{~W}$ type searcher & 4 unit \\
\hline 4 & Wiper & 2 unit \\
\hline 5 & Radio VHF dilengkapi Antena & 1 unit \\
\hline 6 & GPS map standar & 1 unit \\
\hline 7 & Kompas air raksa 4 inch & $1 \mathrm{pcs}$ \\
\hline 8 & Bendera nasional & 2 pcs \\
\hline 9 & Lampu senter 3 batterey & 2 pcs \\
\hline E. & Perlengkapan Keselamatan & \\
\hline 1 & Ring buoy & 1 pcs \\
\hline 2 & Life jacket & 10 pcs \\
\hline 3 & Pemadam api portable klas ABC & 1 pcs \\
\hline 4 & Kotak P3K + isi & 1 pcs \\
\hline F. & Perlengkapan Labuh/Tambat & \\
\hline 1 & Tali jangkar nylon 1 inch, $100 \mathrm{~m}$ & 2 unit \\
\hline 2 & Tali tambat nylon 1 inch. $40 \mathrm{~m}$ & 4 unit \\
\hline 3 & $\begin{array}{l}\text { Jangkar } 15 \mathrm{~kg}+\text { +swivel, shackle dan } \\
\text { rantai } 3 \mathrm{~m}\end{array}$ & 1 unit \\
\hline 4 & Tali buangan & 1 unit \\
\hline 5 & Daprah tipe F4 & 2 pcs \\
\hline
\end{tabular}

e. Tenaga kerja dan waktu pelaksanaan produksi

Jumlah tenaga yang dibutuhkan untuk membuat unit moulded parmanen dan produksi unit kapal patroli tipe $V_{21}$ berbahan fiber glass dengan waktu pelaksanaan sebagaimana yang diperlihatkan pada tabel.6

Tabel.6 Jumlah Hari/Orang untuk membuat cetakan parmanen/unit produksi kapal

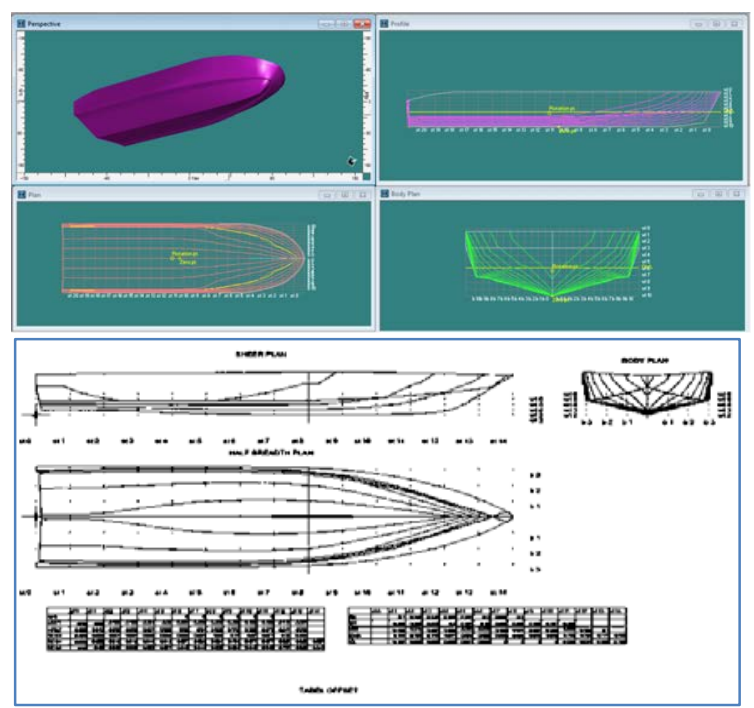

Gambar 5. Model dan lines plan kapal patroli 30 tipe $\mathrm{V}_{21}$ fiber glass

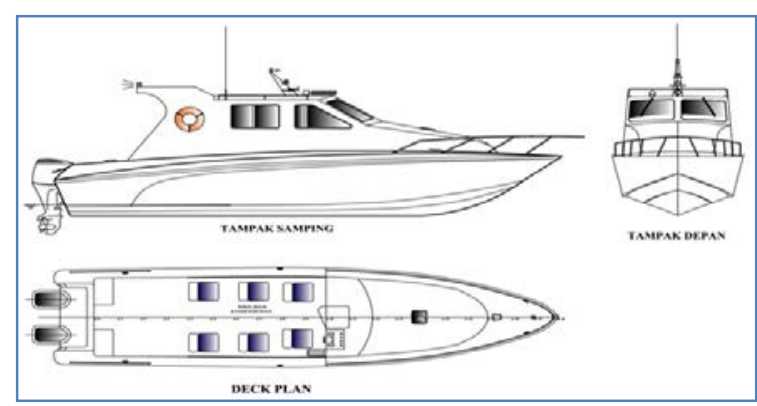

Gambar 6. General Arrangement kapal patroli Tipe $\mathrm{V}_{21}$ fiber glas

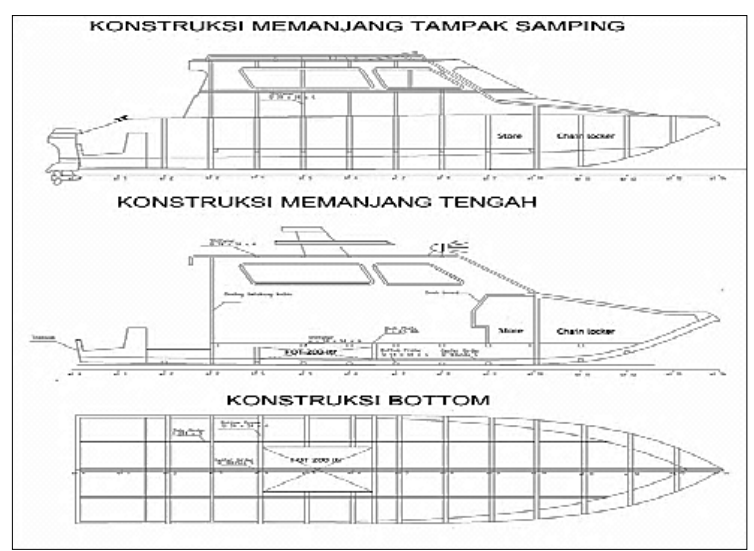

Gambar 7. Gambar Konstruksi kapal patroli Tipe $\mathrm{V}_{\mathbf{2 1}}$ fiber glass

\subsection{Biaya Produksi Kapal}

Biaya produksi kapal patroli tipe $\mathrm{V}_{21}$ fiber glass yang direncanakan, mengacu pada harga satuan bahan/material/peralatan/ komponen kapal yang 
marine use disertai jasa tenaga kerja yang berlaku saat ini.

Adapun rencana biaya produksi kapal dapat diuraikan sesuai tabel.7 sebagai berikut:

Tabel.7 Biaya produksi kapal

\begin{tabular}{|l|l|r|}
\hline No & \multicolumn{1}{|c|}{ Uraian Iten Anggaran } & \multicolumn{1}{|c|}{$\begin{array}{c}\text { Jumlah } \\
\text { (Rp) }\end{array}$} \\
\hline 1. & $\begin{array}{l}\text { Pembuatan moulded } \\
\text { parmanen serta unit hull/deck }\end{array}$ & 174220000 \\
\hline 2. & Perlengkapan deck & 57075000 \\
\hline 3. & Mesin \& Perlengkapan & 196550000 \\
\hline 4. & Perlengkapan listrik & 9275000 \\
\hline 5. & $\begin{array}{l}\text { Perlengkapan } \\
\text { navigasi/komunikasi }\end{array}$ & 29850000 \\
\hline 6. & Perlengkapan keselamatan & 7500000 \\
\hline 7. & Perlengkapan labuh/tambat & 10750000 \\
\hline 8. & $\begin{array}{l}\text { Jasa pemasangan } \\
\text { perlengkapan \& Supervisi }\end{array}$ & 35000000 \\
\hline 9. & $\begin{array}{l}\text { Peluncuran, sea trial dan surat } \\
\text { kapal }\end{array}$ & 19500000 \\
\hline 10. & $\begin{array}{l}\text { Transportasi \& Biaya tak } \\
\text { terduga lainnya }\end{array}$ & 15000000 \\
\hline & \multicolumn{2}{|c|}{ Total } \\
\hline
\end{tabular}

\section{SIMPULAN}

\section{Kesimpulan}

a. Biaya produksi kapal patroli tipe $\mathrm{V}_{21}$ berbahan fiber glass yang meliputi moulded parmanen dan unit produksi yang terdiri atas bahan/material, peralatan kerja (yang habis terpakai), peralatan/perlengkapan komponen kapal, jasa tenaga kerja, transportasi, peluncuran, sea trial dan ijin berlayar sebesar Rp.554.720.000,(exclude Ppn 10 \% dan Pph 1,5\%). sedangkan total biaya produksi (include Ppn 10 \% dan Pph $1,5 \%)$ sebesar Rp. 611.815.000,- Biaya produksi tersebut tidak termasuk biaya investasi peralatan kerja.

b. Biaya pembuatan moulded parmanen serta unit hull dan deck sebesar Rp. 174.220.000,-

\subsection{Saran}

Untuk membuat rencana anggaran biaya produksi kapal berbahan fiber glass yang akurasi, agar dilakukan perencanaan gambar-gambar desain secara baik dan benar, pembelian bahan/material dan peralatan/perlengkapan bagian komponen kapal yakni yang marine use serta setiap 1 (satu) tahu sekali dilakukan pengecekan harga satuan bahan/material dan peralatan/perlengkapan bagian komponen kapal untuk membuat rencana anggaran biaya produksi kapal

\section{DAFTAR PUSTAKA}

Buana Ma'ruf, Maret, 2011. A Study on Standardization of Fiberglass Ship's Hull Lamination Constructio;

Biro Klasifikasi Indonesia (BKI). 2006, Rules for Non Metallic Materials Part 1;

Marasabessy, Amir. 2015, Prosiding Seminar Nasional Kemaritiman, LPPM Akademi Maritim Nusantara Cilacap;

Maxsurf Automation Manual, Formation Design Systems Pty Ltd 1984 - 2010

De Garmo, E.P. 1999. Ekonomi Teknik, Jilid 1. Jakarta, Indonesia: PT Prehallindo.

Rahmawan, Ferry Rizki, 2013, Analisa harga Satuan Berdasarkan Database, Universitas Pendidikan Indonesia.

CV.Cisanggarung Putra Mandiri (CPM), 2014, Rencana Anggaran Biaya Produksi kapal patroli tipe V21 Fiber glass. 